\title{
Bleaching in Primary Teeth-Mini Review
}

\author{
Attiguppe Ramasetty Prabhakar ${ }^{1}$ and Divya Doddamani ${ }^{2 *}$ \\ ${ }^{1}$ Pedodontics and Preventive Dentistry, Former Head of the Department and \\ Principal, Bapuji Dental College and Hospital, Davangere, Karnataka, India \\ ${ }^{2}$ Pedodontics and Preventive Dentistry, Consultant Pediatric Dentist at Dental Hub, \\ Badiadka, Kasaragod District, Kerala, India \\ *Corresponding Author: Divya Doddamani, Pedodontics and Preventive Dentistry), \\ Consultant Pediatric Dentist at Dental Hub, Badiadka, Kasaragod District, Kerala, \\ India.
}

Received: November 03, 2021

Published: November 25, 2021

(C) All rights are reserved by Attiguppe

Ramasetty Prabhakar and Divya

Doddamani.

\begin{abstract}
Tooth discoloration among children is often accompanied by dissatisfaction in appearance, leading to adverse psychological effects. Aesthetics is a common concern in routine clinical practice and, it is an integral component for psycho-emotional development of the child in its environment. Most of the reviews on bleaching describe bleaching techniques in permanent teeth. This review provides an overview on bleaching of primary teeth and bridges the gap in literature.
\end{abstract}

Keywords: Bleaching Agents; Tooth; Deciduous; Esthetics; Dental

\section{Abbreviations}

CP: Carbamide Peroxide; SP: Sodium Perborate; HP: Hydrogen Peroxide; HO-1: Heme Oxygenase-I; HSP32: Heat Shock Protein 32

\section{Introduction}

Aesthetic dentistry has transformed patients' attitude towards dental treatment. It influences one's self-esteem and confidence in a social setting. A common misconception about aesthetic dentistry is that it is only for adults. Only in recent years, aesthetics is gaining importance in paediatric dentistry due to its direct relationship with emotional and overall well-being of the child [1]. Tooth discoloration due to intrinsic and extrinsic stains represent a challenge to the paediatric dentist. However, in contrast to adult cosmetic dentistry, options in primary teeth are designed to be minimally invasive. Current approaches to the whitening of darkened teeth include tooth bleaching techniques that can be applied by the dentist or patient to both vital and non-vital teeth [2].

\section{History}

1877 - Chapple's first published dental report on tooth bleaching using oxalic acid, 1884 - Harwan used hydrogen peroxide as a bleaching agent, 1895 - Garretson used chlorine to bleach nonvital teeth, 1895 - Westlake enhanced bleaching by electricity, 1911Rosenthal used Ultraviolet rays to enhance bleaching efficacy, 1916 - Walter Kaine bleached fluoresced teeth using muriatic acid (18\% Hydrochloric acid), 1918 -Abbot used 35\% hydrogen peroxide accelerated by heat from a light source, 1924 - Prinz used heated solutions of Superoxol and Sodium perborate for cleaning the pulp chamber, 1970 - Cohen is first to bleach tetracycline-stained teeth using 35\% hydrogen peroxide and a bleaching instrument, 1984 - Zaragoza bleached maxillary and mandibular arches simultaneously with 70\% hydrogen peroxide and water, 1989 - Haywood and Heymann described home bleaching using carbamide peroxide, 1989 - Croll introduced hydrochloric acid paste system for superficial enamel discoloration [3], 2001-Brantly used 10\% carbamide peroxide for primary teeth discolouration [4], 2006 - Bussadori used 35\% hydrogen peroxide for primary teeth discolouration [5], 2009 - Arikan used sodium perborate as bleaching agent in primary teeth [2].

\section{Etiology of primary tooth discolouration}

Factors responsible for primary teeth discolouration can be broadly categorized into intrinsic and extrinsic. Intrinsic factors 
are dental fluorosis, tetracycline stain, enamel, and dentin inherent defects (Amelogenesis imperfecta, Dentin dysplasia, Deciduous molar hypo mineralization, Dentin genesis imperfecta), Hematologic disorders, Pulpal necrosis and endodontic material, Trauma, Root resorption, Dental caries, Erosion. Extrinsic factors include stains (black, green. orange), fluoride pigmentation [6].

Appropriate treatment planning needs correct identification of the etiology.

\begin{tabular}{|c|c|c|}
\hline $\begin{array}{l}\text { N1- Direct } \\
\text { Dental Stain }\end{array}$ & $\begin{array}{l}\text { Chromogen binds to the } \\
\text { tooth surface to cause } \\
\text { discolouration. The colour of } \\
\text { the chromogen is like that of } \\
\text { the dental stain }\end{array}$ & $\begin{array}{c}\text { May be removed or } \\
\text { prevented } \\
\text { satisfactorily by } \\
\text { good oral hygiene } \\
\text { practice }\end{array}$ \\
\hline $\begin{array}{l}\text { N2 - Direct } \\
\text { Dental Stain }\end{array}$ & $\begin{array}{l}\text { Coloured material changes } \\
\text { colour after binding to tooth }\end{array}$ & $\begin{array}{l}\text { Clinically more } \\
\text { difficult to remove } \\
\text { and may require } \\
\text { oral prophylaxis. }\end{array}$ \\
\hline $\begin{array}{l}\text { N3 - Indirect } \\
\text { Dental Stain }\end{array}$ & $\begin{array}{c}\text { Coloured material or } \\
\text { prechromogen binds to the } \\
\text { tooth and undergoes a } \\
\text { chemical reaction leading to } \\
\text { stain }\end{array}$ & $\begin{array}{c}\text { Require oxygenating } \\
\text { agents such as } \\
\text { carbamide peroxide }\end{array}$ \\
\hline
\end{tabular}

Table 1

Nathoos classification of extrinsic stains describes the mechanism of dental stain and the appropriate treatment [7].

Even Intrinsic stains need chemicals such as hydrogen peroxide and sodium perborate to solubilize the chromogens.

\section{Bleaching in primary teeth}

Tooth discoloration within a dental arch may vary significantly during the mixed dentition period. The major reason for that is differences in the thickness of enamel of primary and permanent teeth. There is no literature recommending against the use of bleaching in primary dentition; still clinicians should approach this issue with care [8].

\section{Bleaching techniques in primary teeth}

American Dental Association approved 10\% carbamide peroxide as a bleaching agent for children. The property such as watersoluble and pleasant tasting makes it palatable even for children [4].
Bussadori., et al. Described the use of whitening gel (hydrogen peroxide to one drop of thickener) along with photoactivation for in-office bleaching technique in non-vital primary teeth. Darkened portion of the dentin was removed. Larger access cavity was made for bleaching purpose. Sealing of the chamber was done using conventional glass ionomer cement or resin modified glass ionomer with $2 \mathrm{~mm}$ thickness apically from the

cementoenamel junction. This prevented the bleaching agent to flow to periapical and periodontal tissues, preventing external root resorption [5].

Brantley., et al. Described bleaching of darkened primary teeth without root canal treatment. $10 \%$ carbamide peroxide was used. The tray design was modified in such a way that minimal the amount of bleaching material was used. Use of petroleum jelly minimized the risk of soft tissue contact and decreased the harmful effect. Carbamide peroxide has been used in new-born infants for throat infection, therefore the risk of ingestion is not a greater concern [4].

Gonjito., et al. 37\% carbamide peroxide with a diode laser and another group with a halogen lamp was used in vivo study on primary teeth, Both the groups showed similar results [9].

Arıkan., et al. Described walking bleach technique for the treatment of a darkened primary tooth with sodium perborate. Case was followed up for 1-year. Clinical and radiographical follow-up showed no signs of any pathology [2].

Sharma., et al. Conducted a study understand the effects of bleaching on primary and permanent teeth. Intra-coronal bleaching was performed using sodium perborate. Two months postoperative radiograph showed no signs of external resorption [10].

Ganesh., et al. Conducted an invitro study compared intracoronal bleaching efficiency of $10 \%$ hydrogen peroxide and $10 \%$ carbamide peroxide in primary incisors. Hydrogen peroxide group showed better bleaching effects [11].

Bhatnagar., et al. Found that bleaching agents such as carbamide peroxide (CP), sodium perborate (SP) and hydrogen peroxide (HP) are equally effective in the primary teeth bleaching after 1 week as well as 2 weeks [12]. 
Campos., et al. Conducted a study to assess the difference in the microhardness of the tooth samples treated with 35\% hydrogen peroxide gel, 35\% carbamide peroxide gel, and 35\% carbamide peroxide gel mixed with sodium perborate powder. No significant differences in mean microhardness values were noted [13].

\section{Precautions to take during bleaching among children}

Burning sensation is the most common adverse effect after contact of the bleaching agent with soft tissue. In paediatric dentistry, absolute isolation is necessary to prevent such events. Protective goggles are mandatory due to undesirable and unexpected movements that the child might make. Minimal concentration of the material should be used to avoid dose related consequences [4].

Therefore, American Academy of Paediatric Dentistry encourages: [14]

- The minimal and judicious use of bleaching agent for children.

- Individualized, comprehensive, and sequenced treatment plan for each patient.

- Understanding the adverse effects of bleaching.

- $\quad$ Further research on various bleaching agents.

Advantages of bleaching in children

Compared to restorative materials like composite bleaching gives a more natural appearance to teeth with good esthetic outcomes. Bleaching is a conservative treatment approach with no reduction in the tooth structure [4]. Tooth discoloration can cause discomfort about their appearance that may have serious psychosocial consequences which can be avoided by practicing simple techniques like bleaching the primary teeth [15].

\section{Adverse effects}

Bleaching can have adverse effects. It can be classified as localized and systemic. Localized adverse effects are developing hypersensitivity, interaction with bonding mechanisms wrt to restorative materials such as composite and Glass ionomer cement, external cervical resorption risk, damage and dental material solubility [16].

Systemic adverse effects are (toxicity, free radical, etc.). A histological study confirmed the systemic side effcts of bleaching agents. The study suggested that coronal odontoblasts and endot- helial cells in the underlying pulp tissue may have the potential to respond to oxidative stress by increasing the synthesis of HO-1 (HSP32). This reaction suggests about the systemic adverse effects showing classical inflammatory response [17].

\section{Conclusion}

It can be concluded from this review that bleaching techniques are one of the least invasive solutions to treat primary teeth discoloration. Correct diagnosis, case selection, bleaching materials selection and placement techniques and through understanding of the adverse effects are crucial for the long-term success of such procedures.

\section{Conflict of Interest}

No conflicts of interest.

\section{Bibliography}

1. Christensen John R and Henry Fields "Orthodontic Treatment in the Primary Dentition". Pediatric Dentistry (2019).

2. Arıkan Volkan., et al. "Bleaching a Devital Primary Tooth Using Sodium Perborate with Walking Bleach Technique: A Case Report”. Oral Surgery, Oral Medicine, Oral Pathology, Oral Radiology, and Endodontology 107.5 (2009): 80-84.

3. Fasanaro TomS. "Bleaching Teeth: History, Chemicals, and Methods Used for Common Tooth Discolorations". Journal of Esthetic and Restorative Dentistry 4.3 (1992): 71-78.

4. Brantley DH., et al. "Bleaching primary teeth with $10 \%$ carbamide peroxide". Pediatric Dentistry 23 (2001): 514-516.

5. Kalil Bussadori Sandra., et al. "Bleaching Non-Vital Primary Teeth: Case Report". Journal of Clinical Pediatric Dentistry 30.3 (2006): 179-182.

6. Alazmah Abdulfatah. "Primary Teeth Stains and Discoloration: A Review". Journal of Child Science 11.1 (2021): e20-e27.

7. Nathoo Salim A. "The Chemistry and Mechanisms of Extrinsic and Intrinsic Discoloration". The Journal of the American Dental Association 128 (1998).

8. Metz M J., et al. "Clinical evaluation of $15 \%$ carbamide peroxide on the surface microhardness and shear bond strength of human enamel". Operative Dentistry 32.5 (2007): 427-436.

9. Gonjito IT., et al. "Whitening techniques using the diode laser and halogen lamp in human devitalized primary teeth". Journal of Dentistry for Children 75 (2008): 164-167. 
10. Sharma Divya., et al. "Intra-Coronal Bleaching in Young Permanent and Primary Tooth with Biologic Perspectives". Journal of Clinical Pediatric Dentistry 35.4 (2011): 349-352.

11. Ganesh R., et al. "Comparison of the Bleaching Efficacy of Three Different Agents Used for Intracoronal Bleaching of Discoloured Primary Teeth: An in Vitro Study". Journal of Indian Society of Pedodontics and Preventive Dentistry 31.1 (2013): 17.

12. Patnana Arun K., et al. "Evaluation of Three Different Bleaching Agents in Permanent and Primary Teeth: An in Vitro Study". International Journal of Clinical Pediatric Dentistry 13.2 (2020): 130-135.

13. Faria Campos., et al. "Analysis of Photoreflectance and Microhardness of the Enamel in Primary Teeth Submitted to Different Bleaching Agents". Journal of Clinical Pediatric Dentistry 32.1 (2007): 9-12.

14. "Policy on the Use of Dental Bleaching for Child and Adolescent Patients". Oral Health Policies Use of Dental Bleaching, AAPD (2019).

15. Lima Débora Alves., et al. "Effect of Curing Lights and Bleaching Agents on Physical Properties of a Hybrid Composite Resin". Journal of Esthetic and Restorative Dentistry 20.4 (2008): 266-273.

16. Plotino G., et al. "Nonvital tooth bleaching: a review of the literature and clinical procedures". Journal of Endodontics 34.4 (2008): 394-407.

17. Anderson DG., et al. "A clinical assessment of the effect of $10 \%$ carbamide peroxide gel on human pulp tissue". Journal of Endodontics 25 (1999): 247-250.

Volume 5 Issue 12 December 2021

(C) All rights are reserved by Attiguppe Ramasetty Prabhakar and Divya Doddamani. 